\title{
CNT REINFORCED BASALT FIBER BASED SHIP HULLS
}

\author{
V.Govind ${ }^{\mathbf{1}}$, J.Saravana Kumar ${ }^{2}$, Shyam Venkataraman $\mathbf{V}^{\mathbf{3}}$, C.Elanchezhain ${ }^{\mathbf{4}}$, B.Vijayaramanath ${ }^{\mathbf{5}}$ \\ ${ }^{1}$ Student, Mechanical Engineering, Sri Sairam Engineering College, Tamil nadu, India \\ ${ }^{2}$ Student, Mechanical Engineering, Sri Sairam Engineering College, Tamil nadu, India \\ ${ }^{3}$ Student, Mechanical Engineering, Sri Sairam Engineering College, Tamil nadu, India \\ ${ }^{4}$ Professor, Mechanical Engineering, Sri Sairam Engineering College, Tamil nadu, India \\ ${ }^{5}$ Professor, Mechanical Engineering, Sri Sairam Engineering College, Tamil nadu, India
}

\begin{abstract}
A hull is defined as the body of the ship. It is also one of the major parts of the ship since it carries most of the load. In general, many naval structures such as ships, combatants and small boats are generally made up of steel and aluminium. Even though steel and aluminium provide excellent strength and stiffness value it is highly corrodible and therefore subjected to frequent maintenance schedules. In recent research basalt fiber has grown great importance in naval application. Basalt is generic name for solidified lava which poured out the volcanoes. Basalt is 1/3 of earth Crust. .Basalt fibers were found to have fairly good mechanical properties than other fibers. It exhibits greater tensile strength, very high heat resistance, high impact strength, and strong alkali resistance and low moisture absorption. Basalt products can be used from very low temperatures (about $-200{ }^{\circ}$ C) up to the comparative high temperatures $700-800^{\circ} \mathrm{C}$. Therefore, this paper deals with the reinforcement of continuous basalt fibers with carbon nano tubes which overcomes the disadvantages of corrosion as well as lack of strength in naval structures. This kind of reinforcement is mainly utilized in civil constructions. But when put into use in naval structures it will greatly increase the mechanical properties of ships and lead to an increased performance in ships. This paper deals with the process of integrating basalt fibers into CNT and determining the mechanical properties of the resulting fiber and to determine how the newly created fiber will be useful in tackling the problems that are faced by today`s naval structures.
\end{abstract}

Keywords: Carbon Nano Tubes, Basalt fibre, Mechanical properties, naval structures.

\section{INTRODUCTION}

Most naval ships suffer from lack of strength and effective resistance against corrosion. The conventional steel used possesses greater strength and stiffness but lacks resistance to corrosion. This has been overcome with the use of polymers, but they lack the necessary stiffness. Currently carbon fibers are used as a reinforcement material for polymers used for constructing ship hulls. But carbon fibers are too costly therefore cannot be used in wide range. They are only restricted to special applications .CNT is one of the strongest materials to be synthesized in laboratories. Multiwall carbon nanotubes have the highest tensile strength in comparison with any material yet measured $(63 \mathrm{Gpa})$. When it is utilized in ship construction it can be put to great use by highly improving the resistance of ships to underwater shock loading (UNDEX) as well as improving the mechanical properties of the ship.

\section{BASALT FIBERS}

The main aim of choosing basalt fiber is that it is cheaper and easily available; they cost less than that of glass fiber. Basalt fibers also have fairly good mechanical properties than other fibers currently used. Basalt base composites can replace steel (1 $\mathrm{kg}$ of basalt reinforces equals $9.6 \mathrm{~kg}$ of steel).
Table 1: Properties of Basalt fibre

\begin{tabular}{|l|l|}
\hline Property & Value \\
\hline Tensile strength & $4.84 \mathrm{Gpa}$ \\
\hline Elastic modulus & $89 \mathrm{Gpa}$ \\
\hline Elongation at break & $3.15 \%$ \\
\hline Density & $2.7 \mathrm{~g} / \mathrm{cm}^{3}$ \\
\hline
\end{tabular}

\subsection{Manufacturing of Basalt Fibers}

Basalt fibres are extruded from basalt rocks through a melting process without the application of additives. The manufacturing process can be summarized as shown 


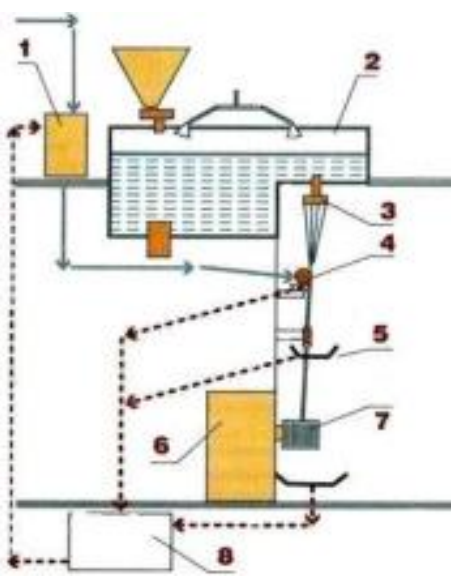

Fig -1: Tank for sizing, 2. Furnace, 3.Bushing, 4. Sizing applicator, 5. Tray for used sizing collection, 6.Winder, 7. Spool, 8. Tank for used sizing

Quarried basalt rock is first crushed, then washed and moved into melting baths in gas-heated furnaces. under temperature of $1460-1500{ }^{\circ} \mathrm{C}$. Here, the process is simpler than glass fibre processing because the basalt fibre has a less complex composition. Molten basalt flows from furnace through a platinum-rhodium bushing with $200,400,800$ or more holes and the fibres can be drawn from the melt under hydrostatic pressure. Then a sizing is applied to the surface of the fibres by a sizing applicator to impart strand integrity, lubricity, and resin compatibility. Finally, a winder allows to realize some large spools of continuous basalt filament. The production process, particularly temperature levels in the furnace, is of considerable importance in relation to final mechanical properties of basalt fibrous materials

\subsection{Method of Integrating CNT into FRP}

The incorporation of CNT with conventional micro scale fibre reinforcements in a common polymer can be achieved by modifying either the matrix resin or the fibre reinforcement using the CNT`s. Modifying the matrix resin by dispersing the CNT`s into the polymer offers the most conventional, easy and compatible method. A number of methods such as shear mixing, calendaring, extrusion, ultrasonication and ball milling. Apart from the above conventional techniques of mixing CNTs with a polymer resin before incorporation with fiber reinforcements, more systematic approaches have been developed to fabricate advanced FRPs, including i) attachment, grafting or growth of CNTs on the reinforcing fibers or fabrics, ii) interleaving bucky papers made from CNTs at certain laminar interfaces, iii) manual spreading or spraying of CNTs on prepregs. The key advantages of direct attachment of CNTs on the fibers/fabrics or interleaving technique are the ability to incorporate CNTs at high concentrations and incorporate the CNTs selectively at the locations of interest within a composite.

\section{MANUFACTURING OF CNT REINFORCED BASALT COMPOSITES}

The method of reinforcing CNT into FRP is either by modifying the resin or by modifying the matrix The fabrication process of multi-scale CNT/epoxy/basalt composites involves mixing Epoxy resin with hardener (2:1 $\mathrm{v} / \mathrm{v})$ was prepared using 2 wt.\% oxidized CNTs., and the composite is cured in an autoclave at $3 \mathrm{kgf} / \mathrm{cm}^{2}$ and $130^{\circ} \mathrm{C}$ for 2 hours.

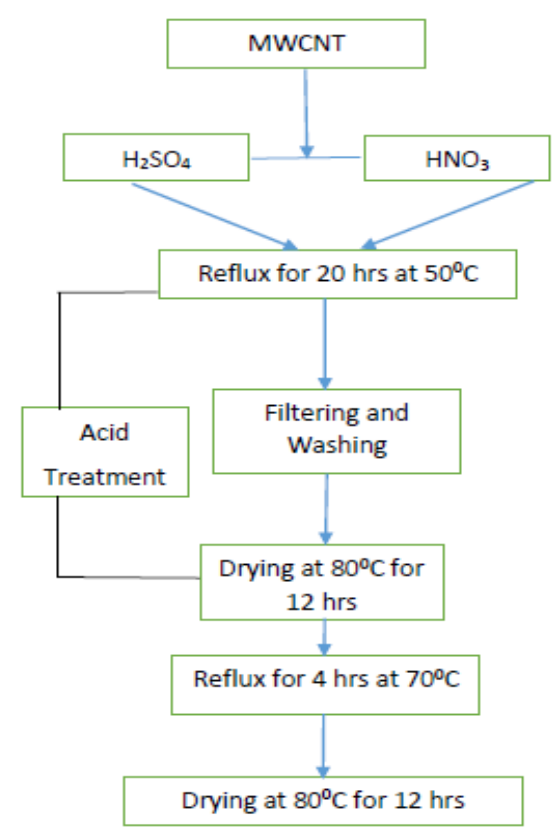

Fig -2: Schematic diagram of preparation of CNT

Tensile properties such as tensile strength, tensile modulus can be determined in accordance with ASTM D3039 standard. Where the standard breadth and length of the test specimen is determined as $25 \mathrm{~mm} * 250 \mathrm{~mm}$, for unidirectional fiber orientation of $0^{0}$ the thickness of the laminate is considered as $1 \mathrm{~mm}$. The tensile specimen is held in a testing machine by wedge action grips and pulled at a recommended cross-head speed of $2 \mathrm{~mm} / \mathrm{min}(0.08 \mathrm{in} . / \mathrm{min})$. Longitudinal and transverse strains are measured employing electrical resistance strain gages that are bonded in the gage section of the specimen.

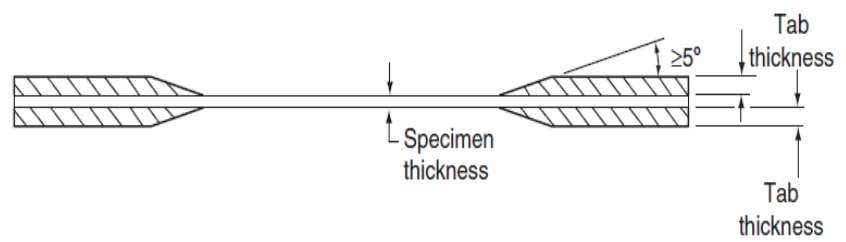

Fig -3: Tensile test specimen 


\section{STRESSES ACTING ON THE SHIP}

Bending moment is the amount of 'bending' the hull experiences. It is highest in the middle and occurs when the hull is bridging 2 waves (sagging or positive bending). Another situation is when a wave is supporting the hull amidships as if the ship was riding a wave (hogging or negative bending).

\subsection{Racking Stress}

In a seaway as a ship rolls from one side to the other the different areas of the ship have motion which are dependent on the nature of the subject area. The accelerations are thus not similar due to the various masses of the different sections (although joined together). These accelerations on the ships structure are liable to cause distortion in the transverse section.

\subsection{Panting}

This is a stress, which occurs at the ends of a vessel due to variations in water pressure on the shell plating as the vessel pitches in a seaway. The effect is accentuated at the bow when making headway.

\subsection{Pounding}

Heavy pitching assisted by heaving as the whole vessel is lifted in a seaway and again as the vessel slams down on the water is known as pounding or slamming. This may subject the forepart to severe blows from the sea. The greatest effect is experienced in the light ship condition.

\subsection{Hogging and Sagging}

Hogging is the stress a ship's hull experiences that cause the center or the hull to bend upward. Sagging is the stress a ship's hull or keel is placed under when a wave is the same length as the ship and the ship is in the trough of two waves. This causes the middle of the ship to bend down slightly, and depending of the level of bend, may cause the hull to snap or crack
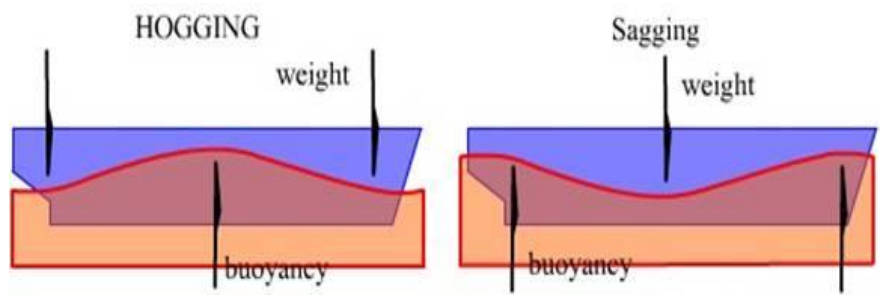

Fig -4: Representation of Sagging and hogging

\section{ANALYSIS}

Stress analysis for conventional ship vessels:

Considering steel grade of A-B-D for building conventional hulls. The value of yield stress is given by the formulae

$$
\begin{aligned}
& R_{e H}=R_{e H o}\left(1.04-\frac{0.75 \theta}{1000}\right) \quad\left(N / \mathrm{mm}^{2}\right) \\
& E=E_{o}\left(1.03-\frac{0.5 \theta}{1000}\right) \quad\left(N / \mathrm{mm}^{2}\right)
\end{aligned}
$$

$\mathrm{R}_{\mathrm{eH} 0}=$ value of the minimum guaranteed yieldstress at ambient temperature

$\mathrm{E}_{0}=$ value of the Young's modulus at ambienttemperature

$\theta=$ service temperature $\left[{ }^{\circ} \mathrm{C}\right]$

Considering the service temperature to be $25^{\circ} \mathrm{C}$.

When steels with a minimum yield stress $R_{\mathrm{eH}}$ greater than 235 $\mathrm{N} / \mathrm{mm}^{2}$ are used, hull scantlings are to be determined by taking into account the material factor $\mathrm{k}$, which can be determined by the formula

$$
k=\frac{295}{R_{e H}+60}
$$

Taking the value of $\mathrm{k}$ as 1 .After calculation the value of $\mathrm{R}_{\mathrm{eH}}$, it is found that $R_{\mathrm{eH}}=235 \mathrm{~N} / \mathrm{mm}^{2}$ for grade A-B-D steel and the young's modulus value $\mathrm{E}=2 * 10^{5} \mathrm{~N} / \mathrm{mm}^{2}$. since the value of young's modulus for CNT reinforced composite is 270 to 920 Gpa and it is found to be more efficient than steel.

\section{THEORETICAL PROPERTIES OF THE COMPOSITE}

The properties of the given matrix can be evaluated using the rule of mixtures and the inverse rule of mixtures. According to the citation given by Smrutisikha Bal [10] ,the properties of CNT is enhanced at $2 \% \mathrm{wt}$. The volume fraction of the fibre is given by using the formula

$V_{f}=\frac{W_{f} / \rho_{f}}{W_{f} / \rho_{f}+\left(1-W_{f}\right) / \rho_{m}}$

Where $V_{f}$ is the volume fraction of the fiber

$W_{f}$ is the weight fraction of the fiber

$\rho_{f}$ is the density of the fiber

$\rho_{m}$ is the density of the matrix

From the properties of basalt fiber and CNT analysed, the value of $\rho_{f}$ is taken as $2.66 \mathrm{~g} / \mathrm{cc}$ and the value of $\rho_{m}$ is taken as $1.33 \mathrm{~g} / \mathrm{cc}$ thus after calculation the theoretical value of the volume fraction of the fiber is $98.6 \%$ and the volume fraction of the matrix is found to be $3.9 \%$ respectively. The density of the composite is calculated using the formula 


$$
\rho=V_{f} \rho_{f}+V_{m} \rho_{m}
$$

By substituting the values of $V_{f}$ and $V_{m}$ respectively in the above equation we get the theoretical density to be equal to $2.607 \mathrm{~g} / \mathrm{cc}$. The longitudinal tensile modulus of the resulting composite is determined using the formula

$E_{L}=E_{f} V_{f}+E_{m} V_{m}=E_{f} V_{f}+E_{m}\left(1-V_{f}\right)=E_{m}+V_{f}\left(E_{f}-E_{m}\right)$

Where $E_{L}$ is the longitudinal tensile modulus

$E_{f}$ is the longitudinal tensile modulus of the fiber

$E_{m}$ is the longitudinal tensile modulus of the matrix

By substituting the values of $E_{m}$ as $54.75 \mathrm{Gpa}$ and $E_{f}$ as

89gpa,we find that the value of $E_{L}$ as $87.63 \mathrm{Gpa}$.

The transverse modulus of the composite is determined using the formula

$$
\frac{1}{E_{T}}=\frac{V_{f}}{E_{f}}+\frac{V_{m}}{E_{m}}
$$

Where $E_{T}$ is the transverse modulus of the composite

$E_{f}$ is the transverse modulus of the fiber

$E_{m}$ is the transverse modulus of the matrix

By substituting the values of $E_{f}$ and $E_{m}$ as $8.27 \mathrm{Gpa}, 5.26 \mathrm{Gpa}$

we get the value of $E_{T}$ as $8.091 \mathrm{Gpa}$.

The enhancement in strength is given by the formula

$$
\Delta G_{I C, S S}=\frac{L V_{f} T L_{P}}{2 r}
$$

Where $\mathrm{L}$ - Length of the fraction in $\mathrm{m}$

$r$ - Radius of the fraction in $m$

$\mathrm{T}$ - Tensile strength in Mpa.

$\mathrm{V}_{\mathrm{f}}-$ Volume fraction

$\mathrm{L}_{\mathrm{p}}$ - Length of pulling of fiber in $\mathrm{m}$

Substituting the corresponding values $\mathrm{r}=7 \mathrm{~nm}, \mathrm{~L}=10 \mu \mathrm{m}, \mathrm{V}_{\mathrm{f}}$ $=1 \%, \mathrm{~T}=10 \mathrm{Mpa}, \mathrm{L}_{\mathrm{p}}=5 \mu \mathrm{m}$ by substituting the above values we get the value of enhancement in toughness to be about $357.14 \mathrm{~m}^{-1}$.

\section{CALCULATION OF QUANTITY OF CNT REQUIRED}

According to the ASTM D3039 the specimen size is $25 \mathrm{~mm} * 250 \mathrm{~mm}$ respectively, thus the area of one test specimen for tensile testing is found out to be $62.5 \mathrm{~cm}^{2}$.In case of adding CNT to the resin, the whole area is considered. As the calculated value of volume fraction of matrix is taken as $3.9 \%$, the area occupied by the matrix is calculated as $2.4375 \mathrm{~cm}^{2}$. Thus the mass of CNT required is evaluated as 6.48375 grams that is approximately equal to 6.5 grams of CNT per test specimen.

\section{ADVANTAGES}

When CNT is reinforced into materials such as fiber glass, plastic or even metals it greatly increases the strength to weight ratio. Due to increased strength to weight ratio the size of the vessel also tremendously increases. This also decreases the fuel consumption of the ships thereby reducing the demand for more fuel, making voyage through ships more efficient and cheaper and affordable by all. Use of MWCNT prevents bio fouling of ship hulls by discouraging attachment of algae and barnacles. Incorporation of CNTs increases anti corrosion resistance for metals. For load bearing application, CNT powders mixed with polymers can increase stiffness and fracture toughness by 6 and $23 \%$ respectively without compromising other mechanical properties. Recent examples of application in marine include light weight wind turbine blades and hulls

\section{CONCLUSIONS}

As the use of CNT as a reinforcing agent for basalt fibers which is used in ship building is found to bring about a great revolution in the field of ship building and construction techniques by increasing various mechanical properties as well as increasing the size of the ships as well as their performance By calculations it can be proved that usage of CNT reinforced basalt fibers will prove highly potential in conventional ship building. At present analysis CNT is young and developing. When utilized fully can be put to good use

\section{REFERENCES}

[1] Jongsung Sim, Cheolwoo Park, Do Young Moon , "Characteristics of basalt fiber as a strengthening materialfor concrete structures"

[2] Kunal Singha , "A short review on basalt fiber"

[3] A.Wei Chen, B. Hongbin Shen ,L. Maria, A.Changzheng Huang,A. Steven Nutt, "Basalt fiberepoxy laminates with functionalized multi-walled carbon nanotubes"

[4] R. Andrews, M.C. Weisenberger, "Carbon nanotube polymer composites"

[5] K. Van de Velde ,P. Kiekens, ,L. Van Langenhove , "Basalt fibre as reinforcement for composites" 
[6] http://en.wikipedia.org/wiki/Hogging_and_sagging/

[7] http://www.google.co.in/?gws_rd=cr\&ei=7EknUqOhH

sOmrAf_k4GYDw\#q=advantages+of+using+Cnt+in+p olymers

[8] http://www.hindawi.com/journals/jnm/2012/262694/

[9] Fiber Reinforced composites- Materials, Manufacturing and design by P.K Mallik

[10] Dispersion and reinforcing mechanism of carbon nanotubes in epoxy nanocomposites SMRUTISIKHA BAL

[11] Longitudinal stiffness characteristics of Uni directional fiber reinforced polymeric composites subjected to tension-Nicolae taranu,Raluca Hohan \& Liliana Bejan

\section{BIOGRAPHIES}

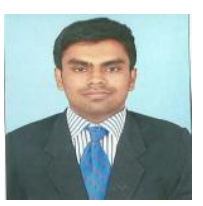

Name: V.Govind, Student at Sri Sairam Engineering college. Department Mechanical Engineering

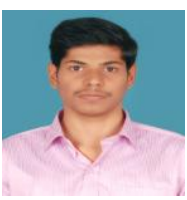

Name: J.Saravana kumar, Student at Sri Sairam Engineering college. Department Mechanical Engineering

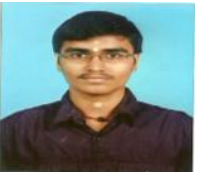

Name: Shyam Venkatramanan V., Student at Sri Sairam Engineering college. Department Mechanical Engineering 